\title{
Análisis de las normativas tributarias 2020, en aplicación con las microempresas de la ciudad de Cuenca.
}

\author{
Analysis of the 2020 tax regulations, in application with the \\ microenterprises of the city of Cuenca.
}

Edison Becerra Molina. ${ }^{1}$ \& Miguel Ángel Neira Cedeño. ${ }^{2}$

DOI: https://doi.org/10.33262/visionariodigital.v5i2.1701

\begin{abstract}
.
This article is grounded on the research project called "Study to determine the importance of accounting and financial information given the uncertainty of Covid19, in the MSMEs in the business environment in Region 6, in the specific case our study is based on the analysis of the new tax obligations, In the specific case our study is based on the analysis of the new tax obligations, with genesis in the city of Cuenca of the MSMEs taxpayers, on the application of the Organic Law of Simplified and Progressive Taxation and its regulations, also including entrepreneurs who meet the condition of microenterprises, as established in the Organic Code of Production, Commerce and Investments. On its part, they will be included in this registry provided that they do not fall within the limitations established in the regulations. The purpose of this study is to determine the behavior of the taxpayers and what its effect will be since they have to accumulate the resources they will need to pay their tax obligations, during the first days of January 2021, as a consequence of the income of the taxable year 2020, the rate of $2 \%$ of the total income from sales imposed on them, regardless of the results of the taxable year. They are part of the micro-entrepreneurial regime, whose annual income or total income is equal to or less than US\$ $300,000.00$, and that have up to 9 workers at the date of publication of the cadastre, for such categorization, the amount of income will prevail over the condition of the number of workers, the tax administration also includes small entrepreneurs, businessmen, natural persons or persons obliged or not to keep accounting, and
\end{abstract}

\footnotetext{
${ }^{1}$ Universidad Católica de Cuenca, Cuenca, Ecuador, jbecerram@ucacue.edu.ec

${ }^{2}$ Universidad Católica de Cuenca, Cuenca, Ecuador, maneirac50@est.ucacue.edu.ec
} 
companies with total income equal to or less than the aforementioned figures stipulated in the regime. To calculate the size of the sample, a target population of the city of Cuenca was set, for which a selection, inclusion and exclusion criterion was carried out, of which 100 people accepted, among them entrepreneurs, microentrepreneurs, persons obliged to keep accounting records and persons not obliged to keep accounting records, through a random environment, in order to know their opinion on the rules and resolutions issued by the Internal Revenue Service.

Keywords: regulations, regime, msmes, obligations, taxpayers.

\section{Resumen.}

Este artículo se basa en el proyecto de investigación denominado "Estudio para determinar la importancia de la información contable y financiera ante la incertidumbre del Covid-19, en la MIPYMES en el entorno de los negocios en la Región 6, en el caso concreto nuestro estudio se asienta en el análisis de las nuevas obligaciones tributarias, con génesis en la ciudad de Cuenca de los contribuyentes de las MIPYMES, sobre la aplicación de la Ley Orgánica de Simplificación y Progresividad Tributaria y su reglamento, se incluyen también a emprendedores que cumplan con la condición de microempresas, según lo establecido en el Código Orgánico de la Producción, Comercio e Inversiones. Por su parte pertenecerán a este catastro siempre que no se encuentren dentro de las limitaciones previstas en la normativa. El propósito de este estudio es determinar el comportamiento de los contribuyentes y cuál será su efecto, ya que tienen que acumular los recursos que necesitarán para pagar sus obligaciones tributarias, durante los primeros días del mes de enero del 2021, consecuencia de los ingresos del ejercicio fiscal del 2020, y la tarifa del $2 \%$ de los ingresos totales por ventas que se les imponen, independientemente de los resultados del ejercicio fiscal. Forman parte del régimen microempresarial, cuyo ingreso anual o ingreso total sea igual o menor a US\$300.000.00, y que cuenten con hasta 9 trabajadores a la fecha de publicación del catastro, para dicha categorización, prevalecerá el monto de ingresos sobre la condición de número de trabajadores, la administración tributaria también incluye a pequeños empresarios, empresarios, personas naturales o personas obligadas o no a llevar contabilidad, y sociedades con ingresos totales iguales o menores a las cifras ya mencionadas estipuladas en el nuevo régimen. Para calcular el tamaño de la muestra el entorno se lo realizo a una población objetiva en la ciudad de cuenca, de manera que se efectuó un criterio de selección, inclusión y exclusión de las cuales 100 personas aceptaron, entre ellas empresarios, microempresarios, personas naturales obligadas a llevar contabilidad, personas naturales no obligadas a llevar contabilidad, mediante un ambiente aleatorio, para de esa manera conocer su opinión sobre la normativa y resoluciones emitiditas por el Servicio de Rentas Internas. La metodología utilizada en el estudio se describe a partir del análisis bibliográfico, y la aplicación del instrumento del cuestionario, que permitió revisar, analizar, diagnosticar y determinar los efectos que pueda propiciar. Los resultados obtenidos demuestran que es necesario una actualización al Catastro y Reforma de la Ley Orgánica de Simplificación y progresividad Tributaria, con respecto a establecer una 
excepción al pago del impuesto del $2 \%$ sobre las ventas en el caso de los Microempresarios que registren pérdidas en el periodo fiscal.

Palabras clave: normativa, régimen, mipymes, obligaciones, contribuyentes

\section{Introducción.}

Este articulo está centrado en las nuevas normativas tributarias que se deben seguir desde inicios del ejercicio 2020 como la Ley de Simplicidad y Progresividad Tributaria que entró en vigencia en Ecuador, tras su publicación en el Registro Oficial el martes 31 de diciembre del 2019.

La nueva Ley plantea cambios como gravar con impuesto a la renta a las ganancias que pagan las empresas, según el Servicio de Rentas Internas (2020) y del nuevo régimen tributario más simple para las microempresas que es el tema en el cual se va a centrar este artículo.

Las microempresas, conforme la Ley Orgánica de Simplificación y Progresividad Tributaria (2019), y el Reglamento a la Ley Orgánica de Simplificación y Progresividad Tributaria (2020), en sus artículos 97.17 y 253.3, respectivamente, permanecerán en este régimen, mientras perdure su condición, sin que en ningún caso su permanencia sea mayor a cinco ejercicios fiscales, posteriormente, se sujetarán al régimen general, con esta información en mente, el investigador se propuso analizar las leyes orgánicas de tributación simplificada y tributación progresiva para determinar su impacto en las pymes dado que la mayoría de personas cuestionan si habrá déficit o exención de impuestos al final del año, y si se debe imponer un impuesto al $2 \%$ de los ingresos totales a las MIPYMES.

Los contribuyentes al sujetarse obligatoriamente a este régimen, deben estar dentro del catastro, para lo cual el Servicio de Rentas Internas implementará los sistemas necesarios para el efecto. De allí que el Servicio de Rentas Internas podrá realizar de oficio la inclusión a este Régimen, cuando el contribuyente cumpla las condiciones establecidas para el efecto.

De conformidad con el artículo 300 de la Constitución de la República del Ecuador (2008), el régimen tributario se regirá por los principios de generalidad, progresividad, eficiencia, simplicidad administrativa, irretroactividad, equidad, transparencia y suficiencia recaudatoria. Se priorizarán los impuestos directos y progresivos, la política tributaria promoverá la redistribución y estimulará el empleo, la producción de bienes y servicios y conductas ecológicas, sociales y económicas responsables.

\section{Metodología.}

En un sentido metodológico, esta investigación permite establecer la mejor forma de rastrear aspectos relacionados, pudiendo inferir objetivamente los resultados, de manera de obtener una aproximación de la causa o hecho del fenómeno en estudio. Esta 
investigación se basa en datos del sector de la microempresa, para llevar a cabo este trabajo se realizó una recopilación de datos para comprender las principales fuentes de su impacto en el desarrollo de las actividades económicas, además de establecer una cadena de valor en cada etapa de la investigación para descubrir la causa y el efecto de la ocurrencia y así lograr especificar los objetivos establecidos, este método es necesario debido a la gran cantidad de datos a procesar.

El tipo de investigación es diseño de campo, que se emplea extrayendo datos e indagaciones directamente de la realidad a través del uso de procedimientos de recolección (como entrevistas o encuestas) con el fin de dar respuesta a alguna situación o problema planteado previamente, según Arias (2016) la investigación de campo o diseño de campo consiste en:

La recolección de datos directamente de los sujetos investigados, o de la realidad donde ocurren los hechos, (datos primarios), sin manipular o controlar variable alguna, es decir el investigador obtiene la información, pero no altera las condiciones existentes. De allí su carácter de investigación no experimental (p.25).

Con relación al nivel descriptivo Arias (2012), señala que: "La investigación descriptiva consiste en la caracterización de un hecho, fenómeno, individuo o grupo, con el fin de establecer su estructura o comportamiento" (p.24).

Se entiende por población "Un conjunto finito o infinito de elementos con características comunes, para los cuales serán extensivas las conclusiones de la investigación. Esta queda delimitada por el problema y por los objetivos del estudio" (Arias, 2016, p. 81).

En el caso de la presente investigación, se utilizó el muestreo estratificado, que según Arias (2016) consiste en: "Dividir la población en subconjuntos cuyos elementos posean características comunes, es decir, extractos homogéneos en su interior. Posteriormente se hace la escogencia al azar en cada extracto" (p. 33), por su parte la población estuvo conformada por el universo de 45.814 microempresas, información tomada del catastro del Servicio de Rentas Internas (2021), para calcular el tamaño de la muestra el entorno se lo realizo a una población objetiva en la ciudad de Cuenca, de manera que se efectuó un criterio de selección, inclusión y exclusión de las cuales 100 microempresarios fueron encuestadas, entre ellas empresarios, microempresarios, personas naturales obligadas a llevar contabilidad, personas naturales no obligadas a llevar contabilidad.

El procedimiento y análisis de la información se especifica en forma clara, precisando cuándo y cómo se llevaron a cabo la recogida de los datos. Tal como señala, Pérez (2016), se trata de una fase de búsqueda sistemática reflexiva de la información que hemos recabado y se ha de llevar a cabo el análisis pretendido sobre el estudio con el fin de expresarlos numérica y gráficamente.

\section{Fundamentación Teórica}

El marco teórico referencial comprende aspectos teóricos, conceptuales, legales y situacionales de la realidad que forman parte de la presente investigación, en tal sentido, 
el artículo 83 de la Constitución de la República del Ecuador (2008), establece que son deberes y responsabilidades de los habitantes del Ecuador acatar y cumplir con la Constitución, la ley y las decisiones legítimas de autoridad competente, cooperar con el Estado y la comunidad en la seguridad social y pagar los tributos establecidos por ley; Recordemos que un régimen impositivo, en este sentido, refiere a la legislación que fija el pago de impuestos en un determinado territorio.

De acuerdo con Nicole (2017). Máster en Economía de University College London. Especialista en temas de microeconomía, regulación y defensa de la competencia menciona que: El tributo es un pago que el Estado exige a sus ciudadanos con el fin de financiar sus actividades y/o políticas económicas, es una prestación pecuniaria que el Estado o Administración Pública puede exigir a los ciudadanos de un país o territorio. La cuantía y período de pago de los tributos se encuentra especificada por Ley y su incumplimiento puede llevar a sanciones monetarias y/o la cárcel.

Altamirano Villacís, Gladys Tatiana (2012) en el artículo nacional publicado referente a los tributos señala que América Latina está conformada por distintas realidades a las de los países de la OCDE. Las tasas impositivas bajas sobre la renta, la evasión, las exenciones, las deducciones, los vacíos legales, la elevada desigualdad económica, la informalidad extensa y compleja, son factores que han influido para que la recaudación impositiva en América Latina sea baja y difícil de recaudar. Mientras que, en los países de la La Organización para la Cooperación y el Desarrollo Económicos- OCDE., la recaudación es superior debido a que: las tasas impositivas sobre la renta son elevadas, la informalidad es una cuestión de evasión, los ingresos no gozan de exenciones, la normativa tributaria es de fácil aplicación.

El principio de Progresividad Tributaria, según el Servicio de Rentas Internas (2021), plantea la necesidad de recaudar impuestos gradualmente a los ciudadanos en función de la capacidad de pago personal de cada individuo, un impuesto justo es el que mide la capacidad económica de cada ciudadano por lo que las personas con más recursos deben hacer más aportes que los que tienen menos recursos, en aplicación de este principio el impuesto se impone progresivamente según los ingresos o el patrimonio del ciudadano, así que entre más altos más alta será el porcentaje de contribución.

Entonces podemos decir que El Sistema Tributario es un instrumento fundamental de política económica, además de proporcionar recursos al Estado, permite estimular la inversión, el ahorro, el empleo y la redistribución de la riqueza; contribuir a la estabilidad económica; regular conductas nocivas para la salud e incentivar actividades que preserven el medio ambiente.

La Simplicidad Tributaria, conforme el Servicio de Rentas Internas (2021), constituye un verdadero designio para cuyo logro es adoptar una serie de diversas decisiones de orden jurídico como de administrativo orientadas a alcanzar la meta de sistematizar y racionalizar el régimen legal de la materia y el funcionamiento de la administración tributaria para poder desarrollarse de manera sencilla, eficiente y eficaz, dando el óptimo aprovechamiento de los recursos. 
En síntesis, el concepto de simplificar pone de manera la conveniencia de ordenar, metodizar y racionalizar las distintas fases que conlleva el proceso tributario para de esa forma tener el mejor grado posible de éxito voluntario de las diversas obligaciones, por otra parte, la legislación tributaria constituye el ordenamiento jurídico más analizado y más discutido en razón del beneficio que tiene tanto por la variedad y complejidad de las situaciones que comprende.

Conforme la Ley Orgánica de Simplificación y Progresividad Tributaria (2019), y el Reglamento a la Ley Orgánica de Simplificación y Progresividad Tributaria (2020), en la actualidad los microempresarios o comerciantes, se ven inmersos en la obligación de cumplir con la Administración Tributaria en las distintas contribuciones fiscales que su actividad económica demanda, para lo cual, la misma ha implementado una figura de recaudación especial y simplificada que facilitaría la contribución de tributos a los comerciantes en una figura comprensiva y de fácil utilización; sin embargo, esta nueva figura de recaudación para este sector productivo, implica una serie de afectaciones o cambios en su normal desenvolvimiento.

La Tributación es el recurso básico para el financiamiento del gasto público, para ello los gobiernos de varios países han formulado políticas tributarias en cada país y región, por lo que es muy importante determinar claramente el tamaño del país y sus necesidades en las siguientes áreas. Salud, educación, caminos, servicios básicos, y otras actividades sociales para evitar que el gasto público excesivo y la corrupción afecten el crecimiento económico y aumenten los ingresos en el ámbito social.

Otro punto de vista que tiene esta norma tributaria puede ser que, al pertenecer al régimen de microempresas, los microempresarios pueden cumplir con sus obligaciones tributarias de manera ágil y simplificada. Por tanto, su estructura se basa en tres ejes, que se enumeran a continuación:

El primero, reducir significativamente el número de obligaciones formales de 36 obligaciones generales anuales (48 en algunos casos) a 8 obligaciones anuales, según sea el caso, el segundo apoyar la liquidez del microempresario es uno de los mayores desafíos que enfrenta el emprendedor, y en este caso el microempresario. La flexibilidad de presentar sus obligaciones tributarias semestralmente le brinda al contribuyente varios meses de asistencia de liquidez. Por otro lado, se debe tener en cuenta que con la nueva normativa las obligaciones tributarias no se pagan mensualmente, sino semestralmente. El tercero, agiliza y simplifica el cumplimiento de las obligaciones para que la aportación fiscal sea rápida y sencilla. Este sistema tiene una cierta tasa de ingresos. Además, ofrece al empresario el control de su beneficio y, en consecuencia, evita todas las cargas operativas que resultarían de la regulación general para el cálculo del impuesto sobre la renta.

De igual manera las obligaciones de los contribuyentes sujetos al régimen de microempresas deberán cumplir con los deberes formales y materiales previstos en la ley, incluyendo los siguientes: 
$\checkmark$ Las sociedades estarán obligadas a llevar contabilidad de conformidad con la normativa prevista por el órgano que control. En el caso de las personas naturales, si están obligadas a llevar contabilidad deberán hacerlo bajo las Normas Internacionales de Información Financiera para PYMES.

$\checkmark$ Están obligados a emitir comprobantes de venta, retención y documentos complementarios en los casos que proceda. Los documentos deberán llevar la leyenda "Contribuyente Régimen Microempresas".

$\checkmark$ Están obligados a realizar la liquidación, declaración y pago del impuesto al valor agregado (IVA), impuesto a los consumos especiales (ICE) e impuesto a la renta en forma semestral, en los meses de julio (primer semestre) y enero (segundo semestre). No obstante, puede realizar la declaración de IVA e ICE de manera mensual, durante todo el ejercicio fiscal.

Los sujetos pasivos deberán presentar la declaración anual del impuesto a la renta, los contribuyentes que se encuentren obligados a la presentación del Anexo Transaccional Simplificado (ATS), deberán hacerlo en forma semestral. Si eligiesen presentar la declaración del IVA de forma mensual, el ATS deberá presentarse también de forma mensual, los contribuyentes que se encuentren obligados a la presentación del Anexo ICE deberán hacerlo en forma semestral. Si eligiesen presentar la declaración del ICE de forma mensual, el anexo deberá presentarse también de forma mensual.

Referente a las retenciones en la fuente los contribuyentes sujetos al sistema tributario de pequeñas empresas no serán agentes de retención de impuestos para el impuesto sobre la renta o el impuesto al valor agregado a menos que estén clasificados como contribuyentes especiales o agentes de retención de impuestos por el SRI, y otras circunstancias estipuladas por la normativa, Sin embargo, a los contribuyentes sujetos al sistema se les retendrá el impuesto sobre la renta y el impuesto al valor agregado.

En cuanto al impuesto sobre la renta, el porcentaje de actividades empresariales sujetas al sistema es del 1,75\%. Si los contribuyentes reciben rentas de fuentes distintas a las actividades comerciales sujetas al sistema, estas rentas estarán sujetas al porcentaje de retención especificado en la ley tributaria vigente.

Si los contribuyentes sujetos al régimen hubieren efectuado retenciones en la fuente, deberán declararlas y pagarlas de la siguiente manera: Retenciones de impuesto al valor agregado en forma mensual o semestral, según hayan elegido la periodicidad de su declaración de IVA.

Además de las retenciones de impuesto a la renta en forma semestral, en los meses de julio -primer semestre y enero -segundo semestre, si el contribuyente no realizó retenciones no deberá presentar la declaración.

Referente a los anexos los sujetos al Régimen impositivo para Microempresas pueden enviar en forma semestral el ATS, si optan por la presentación semestral deberán presentar: en agosto la información de enero a junio y en febrero del siguiente año la información de julio a diciembre. 
Los sujetos al Régimen Impositivo para Microempresas obligados a presentar el Anexo ICE, deberán enviarlo de forma semestral en julio la información de enero a junio y en enero del siguiente año la información de julio a diciembre.

Los contribuyentes incorporados a este régimen serán sujeto de retención en la fuente de impuesto a la renta en el porcentaje de $1,75 \%$.

Si los créditos tributarios aplicables del Impuesto a la Renta son mayores al impuesto causado o no existe impuesto se podrá solicitar la devolución del exceso, o presentar el reclamo de pago indebido o utilizarlo directamente como crédito tributario sin intereses el impuesto a la renta anual que causa en los ejercicios impositivos posteriores, según las condiciones establecidas en el artículo 47 de la ley de régimen tributario interno obligatorio.

El crédito tributario se sustenta únicamente con comprobantes de retención en la fuente originales o copias certificadas, mismo que deben mantenerse en los archivos por un periodo no menor a 7 años, el vencimiento de declaraciones semestrales, según el noveno dígito del RUC.

Tabla 1. Cuestiones trascendentes sobre Impuesto a la Renta Microempresas

\begin{tabular}{l|l}
\hline Numero & Resumen \\
\hline \multirow{3}{*}{1} & $\begin{array}{l}\text { Si una persona natural que está dentro del catastro } \\
\text { de Microempresas, y ha obtenido únicamente ingresos por } \\
\text { servicios profesionales, debe declarar en enero el IR en el } \\
\text { formulario 125 en cero. }\end{array}$ \\
\hline \multirow{2}{*}{2} & $\begin{array}{l}\text { Si un profesional aunque esté dentro del catastro de } \\
\text { Microempresas, debe declarar en marzo el impuesto a la renta } \\
\text { por servicios profesionales, además de rendimientos financieros, } \\
\text { ingresos recibidos por herencias, legados y donaciones, premios, } \\
\text { dividendos, pensiones jubilares }\end{array}$ \\
\hline 4 & $\begin{array}{l}\text { Las retenciones correspondientes a servicios profesionales de las } \\
\text { personas se liquidan con la declaración de impuesto a la renta en } \\
\text { marzo 2021. }\end{array}$ \\
\hline 5 & $\begin{array}{l}\text { Las retenciones correspondientes a actividades empresariales de } \\
\text { las personas naturales se liquidan con la declaración de impuesto } \\
\text { a la renta en enero 2021. }\end{array}$ \\
\hline \multirow{2}{*}{5} & $\begin{array}{l}\text { La deducción de gastos personales se realizará en la declaración } \\
\text { de impuesto a la renta que debe prepararse en el mes de marzo } \\
\text { de 2021 }\end{array}$ \\
\hline
\end{tabular}


Una empresa que está dentro del catastro de Microempresas, debe declarar en marzo sus otros ingresos. (F. 101): rendimientos financieros, revalorización de activos, premios de loterías, rifas y apuestas, regalías, los provenientes del exterior que hayan sido sometidos a imposición en otro Estado, enajenación ocasional de bienes muebles o inmuebles, dividendos.

\begin{tabular}{l|l}
\hline 8 & $\begin{array}{l}\text { El impuesto a la renta correspondiente al régimen de } \\
\text { microempresa se aplica el } 2 \% \text { a los ingresos de actividades } \\
\text { empresariales. }\end{array}$ \\
\hline 9 & $\begin{array}{l}\text { El impuesto a la renta para empresas dentro del régimen de } \\
\text { microempresa en actividades excluyentes, se mantiene en } 22 \% .\end{array}$ \\
\hline 10 & $\begin{array}{l}\text { El impuesto a la renta para personas naturales dentro } \\
\text { del régimen de microempresa en actividades excluyentes, se } \\
\text { calcula según la tabla de impuesto a la renta. }\end{array}$ \\
\hline
\end{tabular}

Fuente: Elaboración propia (2021), Basado en las resoluciones del SRI.

Con base en diversos razonamientos legales y las normas antes mencionadas, se puede determinar que en el Ecuador la tributación es exigida por el Estado al contribuyente a través del Servicio de Rentas Internos (SRI). Los principios de universalidad, igualdad, sencillez, proporcionalidad, avance y no trazabilidad son la ley aplicable.

Desde que entró en vigencia la Ley de Reforma de Equidad Tributaria de Ecuador en 2010, el enfoque ha sido mejorar la distribución de la riqueza y combinarla con los objetivos del Plan Nacional de Vida Mejor para la Vida (2017-2021), con el eje dos como concepto de la "economía de los servicios sociales" es muy común, y es necesario de acuerdo con el principio de responsabilidad fiscal compartida y solidaria, implementar una política fiscal integral e inclusiva dirigida a fortalecer la cultura tributaria; mejorar la eficiencia y el progreso de la recaudación; optimizar el gasto calidad; y mejorar la madurez del financiamiento público. Por tanto, todos los procesos tributarios se utilizan principalmente para la recaudación directa de impuestos y el proyecto de ley de organizaciones de apoyo humanitario que está tramitando la Asamblea Nacional en respuesta a la crisis de salud derivada del COVID 19 se considera como lema de trabajo muy urgente en asuntos económicos.

La revisión de la normativa tiene como objetivo imponer impuestos a los contribuyentes en función de su capacidad real de pago, de modo que los impuestos recaudados beneficien directamente a las personas, especialmente a los sectores más vulnerables.

Asimismo, el sistema tributario es un medio básico de política económica, además de proporcionar recursos al país, también puede estimular la inversión, el ahorro, el empleo y la redistribución de la riqueza; promover la estabilidad económica; regular los comportamientos nocivos para la salud y fomentar la protección del medio ambiente.

Del mismo modo, es necesario reconocer que la promoción de actividades exportadoras y la creación de nuevas empresas son el eje horizontal de las políticas públicas y 
económicas, porque estas actividades pueden promover el desarrollo económico y generar así ingresos fiscales de largo plazo sustentables.

A efectos fiscales, la clasificación de MIPYMES puede ser aplicada y controlada por el Servicio de Impuestos Internos de los Estados Unidos con base en la información sobre el monto de ingresos en su base de datos, sin afectar la obligación del contribuyente de registrarse en la entidad. Leyes y regulaciones aplicables.

Para las pequeñas, medianas y grandes empresas con mayores ingresos y no consideradas en el catastro de microempresas, estarán sujetas al sistema general, es decir, continuarán efectuando retención de IVA a partir de abril de 2020, impuesto a la renta (para Bienes son $1,75 \%$ y los servicios $2,75 \%$ ), de acuerdo con las tablas de retenciones existentes para tal efecto, también tributarán al $25 \%$ de la utilidad neta del presente ejercicio.

En cuanto a las micro, medianas y pequeñas empresas (MIPYMES), son servicios, productos o proveedores de otras empresas, cuyo ámbito de negocio abarca los mercados locales, regionales, nacionales e internacionales. La producción y el desarrollo económico del país y su flujo de ingresos, pagan impuestos para el fisco.

Debido a la grave situación que atraviesa el mundo, nuestro país y la región, por la pandemia y el confinamiento, las pequeñas y medianas empresas deben optar por nuevas medidas de desarrollo productivo, estrategias que deben promover el desarrollo de nuevas formas.

La mayoría de los esfuerzos de apoyo a la pequeña y microempresa se han dirigido principalmente hacia programas de crédito que, naturalmente, tienden a absorber la mayor parte de los fondos disponibles. Sin embargo, los microempresarios no siempre necesitan crédito, ni éste es el único servicio financiero que demandan.

Es por tal razón que la economía de una microempresa debe ser bien estudiada para no caer en el error de acceder a créditos cuando la microempresa necesita ampliar su demanda" (Olmedo, 2018).

El espíritu empresarial relacionado con el comercio electrónico, "el proceso de producción, distribución, marketing, venta, transferencia o entrega de productos y servicios a través de medios electrónicos, o el proceso de transferencia de fondos o datos" es una forma de comprar y vender productos a través de redes informáticas en actualidad.

El conocimiento del nacimiento, aplicación, modificación y extinción de los tributos, en articulación de las relaciones jurídicas que se originan entre el Sujeto Activo y el Sujeto Pasivo de la obligación tributaria, es la tarea del Derecho Tributario, (Gonzáles, 2003).

El Derecho Tributario es sin duda la herramienta legal y jurídica que permite viabilizar la tarea fiscal la misma norma y regula las distintas acciones en este sentido permitiendo el reordenamiento del tributo a la par de su practicidad. Por lo tanto, Son prestaciones en dinero, bienes o servicios, determinados por la Ley, que el Estado recibe como ingresos en función de la capacidad económica y contributiva del pueblo, los cuales están 
encaminados a financiar los servicios públicos y otros propósitos de interés general. (Olmedo, 2011).

\section{Resultados.}

Para el presente trabajo de investigación, la recolección de datos fue ordenada, analizada e interpretada, utilizando cálculos estadísticos qué nos proporciona la suite de Office; especialmente el programa Microsoft Word, elaboración de borradores y documentos finales, así como Microsoft Excel para listas Datos, gráficos, tablas estadísticas.

Las encuestas fueron realizadas en la ciudad de cuenca, a los microempresarios relacionados con el Régimen Simplificado para microempresarios y de distintos sectores dentro de la ciudad, los resultados presentados a continuación son las opiniones expuestas de los microempresarios que respondieron a las preguntas emitidas, cabe mencionar que las personas encuestadas en la ciudad fueron seleccionadas al azar en los diferentes locales comerciales de la zona para de esa manera tener una opinión más amplia sobre los nuevos cambios del régimen ya que la finalidad de este estudio es analizar si con estas modificaciones actuales se está cumpliendo su objetivo como instrumento para: i) incorporar y mantener a los individuos y a los dueños de pequeños negocios en el sistema tributario y ii) mejorar el nivel de formalización de la economía.

La tabulación e interpretación de los cuestionarios dirigidos a los Microempresarios de la ciudad de Cuenca, se detalla a continuación.

Figura 1. ¿Usted ha escuchado sobre quiénes están sujetos al Régimen Impositivo para Microempresas?

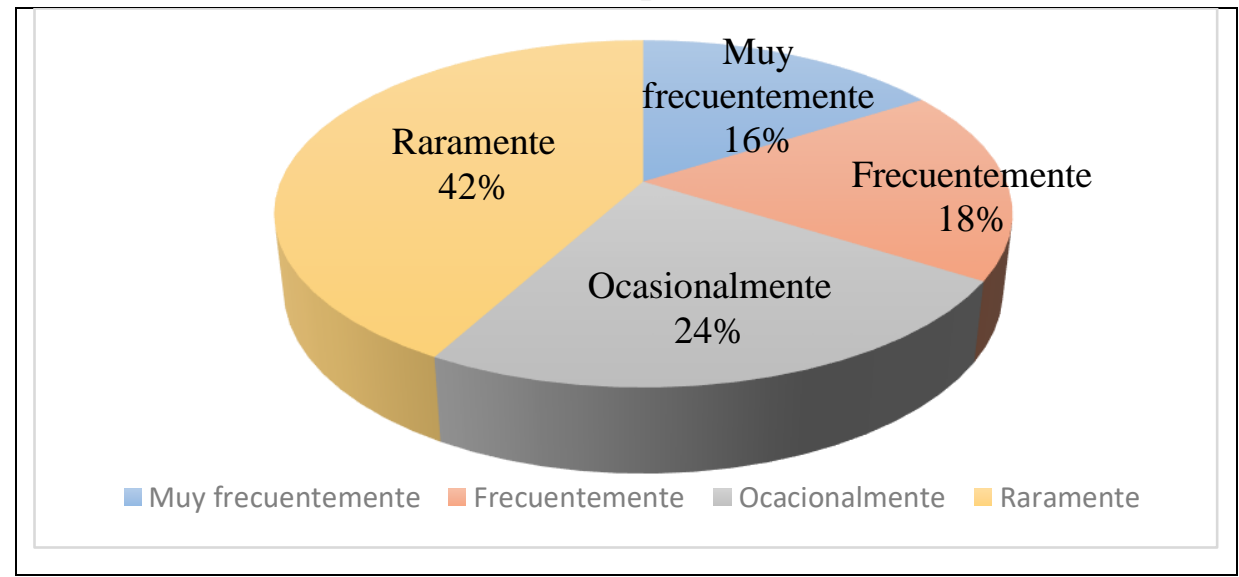

Fuente: Investigación propia (2021).

El resultado de la encuesta con relación a la primera pregunta nos permite ver que el $16 \%$ de las personas muy frecuentemente han escuchado sobre el nuevo régimen impositivo, el $18 \%$ de la población respondió que frecuentemente ha escuchado sobre este nuevo régimen, que sumando los dos porcentajes nos da un valor de $34 \%$ que tienen conocimiento sobre estas nuevas medidas que representa una cantidad muy baja para un régimen que abarca a todos los microempresarios, el 24\% respondió que ocasionalmente han escuchado sobre estas medidas y el $42 \%$ que raramente están informados, de igual manera sumando los dos resultados nos da un valor del 66\%, esto quiere decir que la 
mayoría de la población en este caso microempresarios desconoce totalmente los parámetros del nuevo régimen.

Figura 2. ¿La nueva ley de Régimen Impositivo beneficia a los microempresarios?

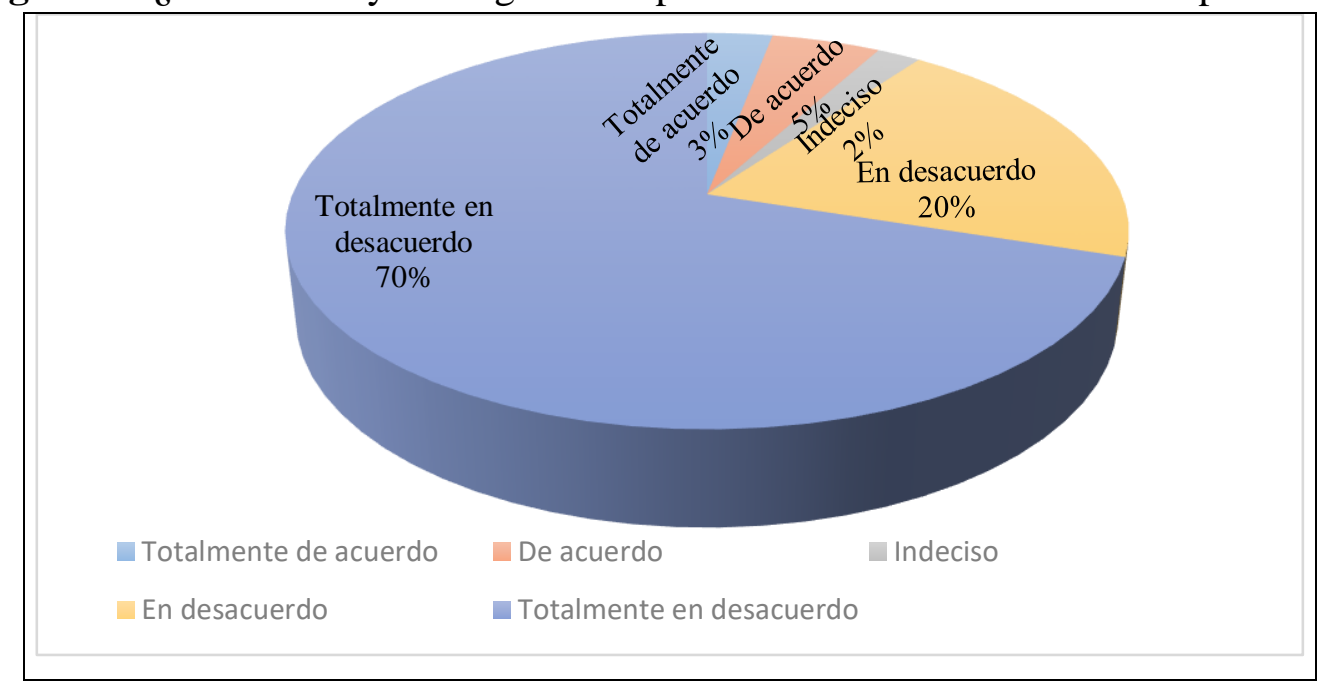

Fuente: Investigación propia (2021).

En el segundo grafico podemos observar que el 3\% está totalmente de acuerdo en que la nueva ley tiene beneficios para los microempresarios y el 5\% está de acuerdo, si sumamos los porcentajes nos da un total de $8 \%$ de aceptación para este régimen que como podemos observar es muy bajo, por otra parte el $5 \%$ señalo que están indecisos, esto por motivos de que desconocen los lineamientos y limitaciones del sistema y las nuevas normas que con ella se debe cumplir, el $20 \%$ señaló que está en desacuerdo ya que no les parece pertinente que el nuevo régimen sea obligatorio, y el $70 \%$ de las personas encuestadas señalaron que están en total desacuerdo con las normas establecidas por el pago del $2 \%$ y la nueva forma para las declaraciones de IVA y el cambio en las retenciones, sumando los dos porcentajes nos da un valor del $80 \%$ que no están de acuerdo con estas normas, esto da entender que el nuevo régimen para los microempresarios o nuevos emprendedores es perjudicial, además de tener desconocimiento los contribuyentes de la aplicación de las nuevas obligaciones tributarias.

Figura 3. ¿Está de acuerdo con el régimen impositivo sobre los tiempos que brinda para las obligaciones tributarias?

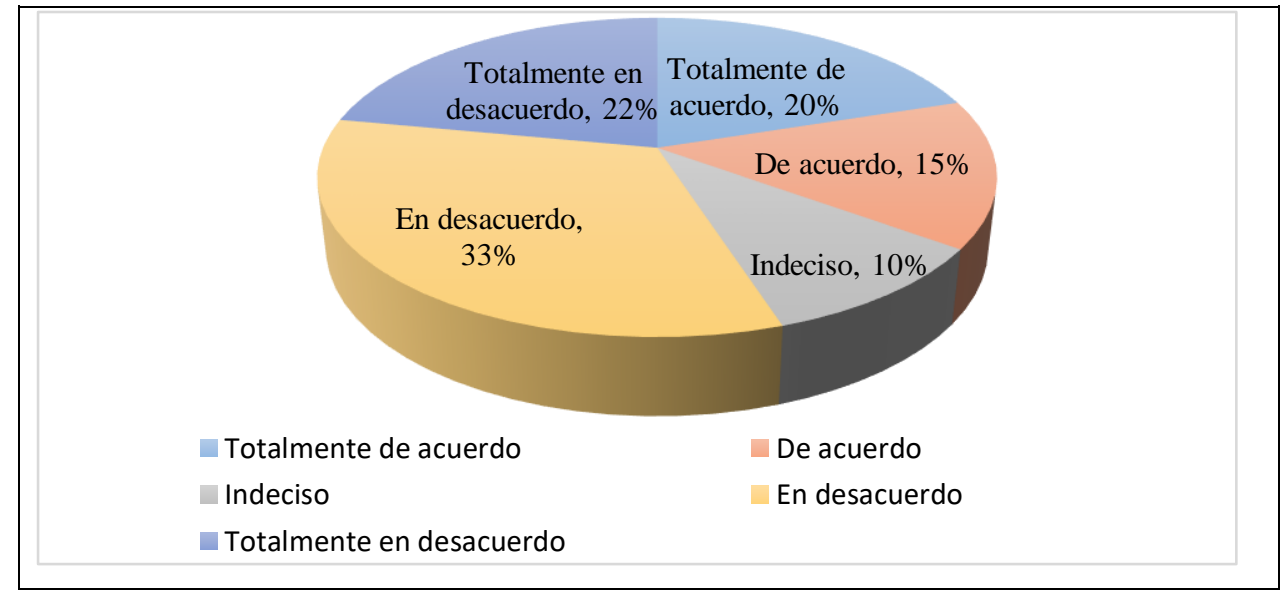

Fuente: Investigación propia (2021). 
El tercer grafico nos señala que el $20 \%$ de las personas encuestadas está totalmente de acuerdo con los nuevos tiempos establecidos por el régimen para las declaraciones, el $15 \%$ de la población está de acuerdo y de igual manera sumando los dos porcentajes nos da un valor $35 \%$ de la población que está de acuerdo con los tiempos del régimen para las declaraciones, por otro lado, el $10 \%$ está indeciso, toda vez que desconocen las nuevas imposiciones tributarias, el 33\% señalo que está en desacuerdo, mientras que el $22 \%$ nos indicó que están en total desacuerdo por la manera en la que los contribuyentes tienen que obtener el dinero para el pago semestral de las declaraciones del IVA, sumando los dos porcentajes tenemos un valor del $55 \%$ de microempresarios que manifestaron que no están de acuerdo con los nuevos tiempos establecidos por el régimen. De allí que los contribuyentes sujetos al Régimen Impositivo para Microempresas deberán efectuar la liquidación, declaración y pago del impuesto al valor agregado (IVA) en forma semestral, en los meses de julio -primer semestre- y enero -segundo semestre-conforme lo dispuesto en el Reglamento para la aplicación a la Ley de Régimen Tributario Interno. Los contribuyentes sujetos a este régimen, con la presentación de la declaración del período fiscal enero de cada año, se podrán acoger a la forma de declaración mensual hasta las fechas señaladas en el artículo 158 del Reglamento para la aplicación a la Ley de Régimen Tributario Interno.

Figura 4. ¿Las fechas establecidas por el servicio de rentas internas le permite a usted contar con el flujo de efectivo para atender sus necesidades empresariales?

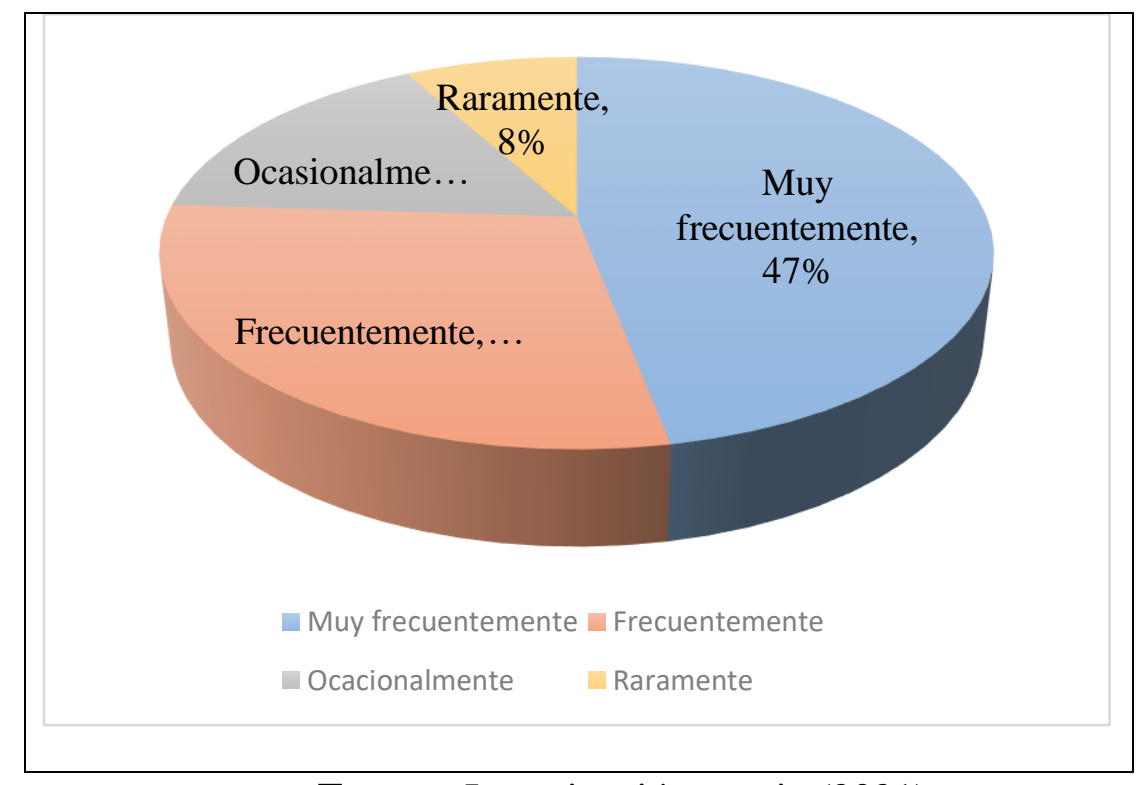

Fuente: Investigación propia (2021).

A continuación, podemos observar que el $47 \%$ respondió que muy frecuentemente la fecha establecida le permite contar con el dinero para atender las necesidades de la empresa, el 29\% respondió que frecuentemente y dada la suma de los dos porcentajes tenemos un $76 \%$ de la población encuestada que cuentan con el flujo de dinero teniendo en cuenta las fechas que establece el servicio de rentas internas, el $16 \%$ señalo que ocasionalmente la fecha no les permite reunir con lo necesario para los gastos de la empresa esto considerando los diferentes tipos de necesidades que tiene cada empresa, el 
$8 \%$ raramente no les da el tiempo para reunir lo que necesiten para los gastos de su actividad económica, sumando los porcentajes nos da un valor del $24 \%$ de microempresarios que con el plazo establecido no cuentan con los recursos para atender sus obligaciones tributarias.

Figura 5. ¿Qué tan fácil o difícil a resultado para usted las nuevas resoluciones y normativa tributaria, impuestas por el servicio de rentas internas para el sector impositivo Microempresarial?

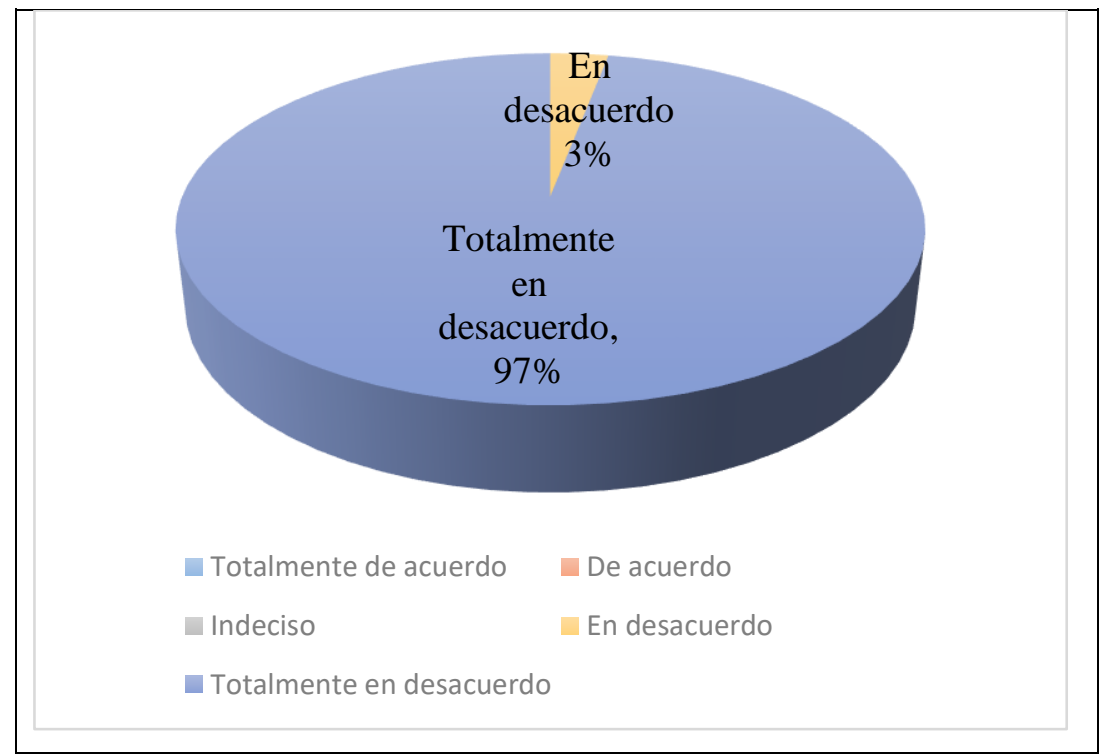

Fuente: Investigación propia (2021).

En la quinta encuesta el 3\% respondió que está en desacuerdo mientras que el 97\% de los microempresarios señalaron que están en total desacuerdo en que el nuevo régimen se haya dado de forma obligatoria ya que esto genera algunos cambios con los cuales no están de acuerdo como los plazos para la declaración del impuesto al valor agregado, el impuesto a la renta que de la misma forma se declara de manera semestral, hay muchas microempresas para las cuales es perjudicial el nuevo régimen, porque aunque tengan pérdidas van a tener que pagar el impuesto a la renta. En tanto que en el régimen general, si es una mediana o una gran empresa, y tiene pérdidas no va a tener que pagar el impuesto a la renta, que corresponde al $2 \%$ de impuesto a la renta sobre los ingresos brutos, menos el valor de devoluciones o descuentos comerciales que correspondan a los ingresos brutos de la actividad empresarial, menos ingresos exentos del impuesto a la renta, menos ajustes de ingresos de la actividad empresarial por efecto de la aplicación de impuestos diferidos por generación, más ajustes en ingresos de la actividad empresarial por efecto de aplicación de impuestos diferidos por reversión, esto da una base imponible para el impuesto a la renta del régimen impositivo para microempresas, de esta base imponible hay que sacar el impuesto a la renta causado, a ello habrá que restar las retenciones en la fuente que le han realizado respecto de los ingresos de la actividad empresarial sujetos al régimen impositivo Microempresarial, que dará como resultado el impuesto a la renta a pagar. Con esta metodología los microempresarios no están de acuerdo, La importancia del sector Microempresarial en el Ecuador se sustenta tanto en el nivel de generación de empleo como en la creación de nuevas oportunidades para las familias más pobres, 
sostienen que esta normativa tributaria limita para impulsar el emprendimiento, quienes son los que marcan la diferencia. No sólo tienen grandes ideas, sino también el impulso para hacerlas realidad, toda vez que utilizan su pensamiento fresco y su trabajo duro para crear un cambio social positivo y coadyuvar al desarrollo del país.

Figura 6. ¿De qué manera considera usted, la importancia el régimen simplificación y progresividad tributaria en las microempresas?

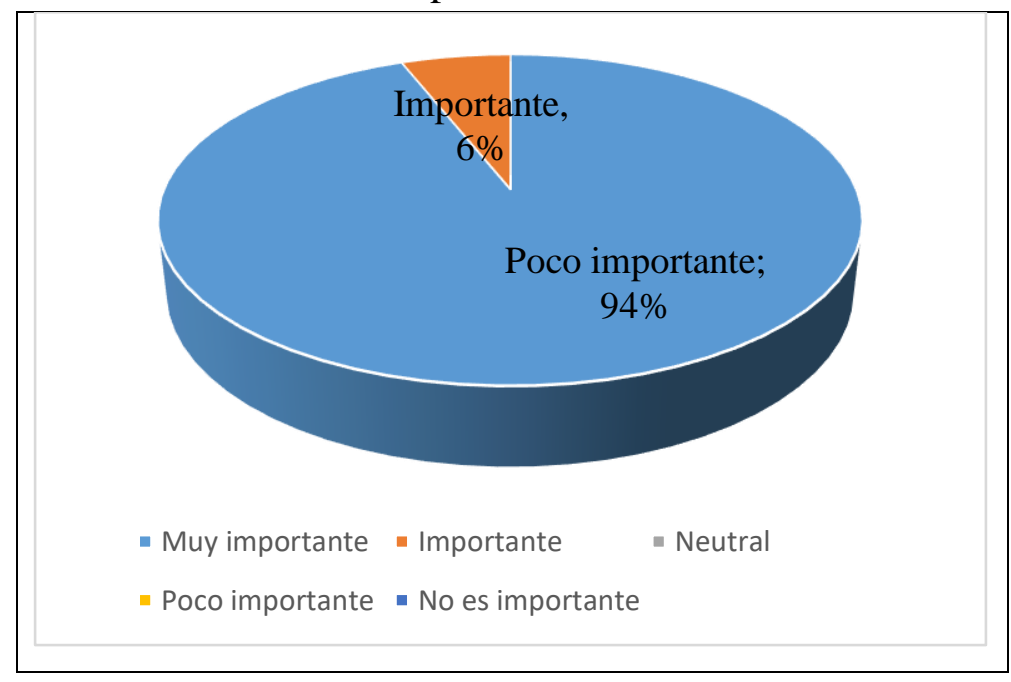

Fuente: Investigación propia (2021).

En la sexta encuesta el resultado nos permite ver que el 6\% señalaron que es importante, mientras que el $94 \%$ de la población en este caso microempresarios opinaron que es poco importante, muchos no entienden el traspaso de personas del régimen general al de microempresarios, esto ha generado confusión e incertidumbre, pues deben someterse a nuevas reglas que muchos desconocen, sostienen que cómo es eso que ahora son muchos microempresarios y deben pagar el $2 \%$ de mi ingreso anual por RUC y tener un sello, sobre sus facturas. Ante el reclamo de la falta de notificaciones sobre la vigencia y ejecución de estos cambios, el SRI sostiene que el catastro es de público conocimiento y está disponible en el portal Institucional.

Figura 7. ¿Está de acuerdo con pagar la tarifa del 2\% del impuesto a la renta sobre los ingresos brutos (sin considerar costos y gastos)?

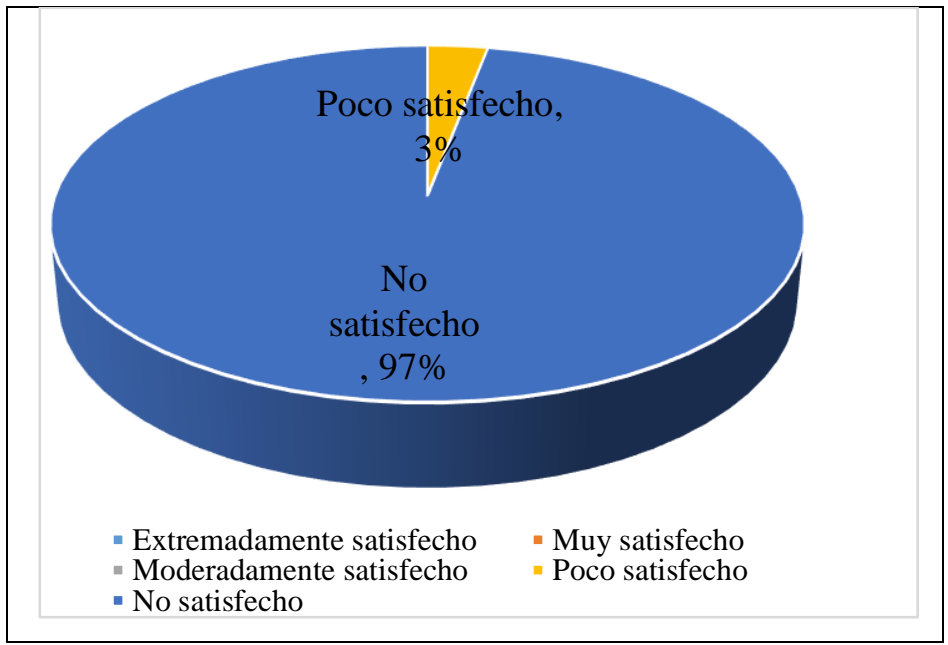

Fuente: Investigación propia (2021). 
El resultado de la última encuesta determina que el 3\% está poco satisfecho y el $97 \%$ señalo que no está satisfecho ya que es un régimen muy insensible al aplicar el $2 \%$ para ingresos netos sin deducciones más que solo retenciones en la fuente y que esto solo atenta contra los emprendedores ya que el hecho de que los microempresarios tengan ingresos, esto no significa que no tengan costos y gastos, de allí que que el impuesto como norma general se grava a la rentabilidad de la actual economía no al ingreso y que en todo caso la inclusión de un nuevo régimen debería ser voluntaria ya que la mayoría de personas encuestadas piensan que la norma infringe el principio de progresividad y de la misma forma el de igualdad ya que perjudica en general a los contribuyentes menores y solamente se podrá deducir los costos y gastos atribuibles a los ingresos de otras fuentes distintas de las actividades sujetas al impuesto a la renta único.

Es importante anotar que los resultados explicados, se muestra objetivamente, donde se evidencian las diferencias entre grupos de estudio y la significación estadística. Es una aproximación a la descripción, comprensión y explicación de los hallazgos derivados de la presente investigación.

\section{Discusión.}

Para la discusión de resultados necesariamente se ha realizado el proceso de recolección de información, a través de datos primarios, tomados directamente de los participantes del estudio mediante entrevistas, cuestionarios, observaciones, mediciones, entre otros, y secundarios, por medio de revisiones de documentos bibliográficos ya existentes como artículos, reportes estadísticos, bases de datos; y, reportes de otras investigaciones.

El régimen impositivo para microempresas es un tema del cual no se ha hablado recientemente ya que desde 1973 se promulga en la ley de fomento de la pequeña industria, esta ley ya toca lo que sería el inicio para los pequeños industriales o los pequeños emprendedores para que se organicen en unidades económicas de producción.

Después en 1997 hasta el 2008 se crean dos leyes, que es la Ley de comercio exterior e inversiones (2008), en la cual ya se determinan las definiciones de emprendimientos o empresas o núcleos de emprendimientos para los fines de exportación, de igual manera se promulga la decisión de la Comunidad Andina de Naciones- CAN, en el artículo 3 de la decisión 702 que hace referencia a la clasificación de las PYMES, este sistema estadístico regional comprenden a todas las empresas formales legalmente constituidas y/o registradas ante las autoridades competentes, que lleven registros contables y/o aporten a la seguridad social, comprendidas dentro de los umbrales establecidos en el artículo anteriormente mencionado.

La Superintendencia de Compañías, Valores y Seguros, mediante resolución, acogió la clasificación de pequeñas y medianas empresas, PYMES, de acuerdo a la normativa implantada por la Comunidad Andina en su Resolución 1260 y la legislación interna vigente, determino la siguiente clasificación de Mipymes. 
Tabla 2. Clasificación De Empresas

\begin{tabular}{c|c|c|c|c}
\hline Variable & Microempresa & $\begin{array}{c}\text { Pequeñas } \\
\text { empresas }\end{array}$ & $\begin{array}{c}\text { Medianas } \\
\text { empresas }\end{array}$ & $\begin{array}{c}\text { Grandes } \\
\text { empresas }\end{array}$ \\
\hline $\begin{array}{c}\text { Personal } \\
\text { Ocupado }\end{array}$ & De 1-9 & De 10-49 & De 50-199 & $>200$ \\
\hline Valor Bruto & $<10000$ & $100.001-$ & $1.000 .001-$ & $>5.000 .000$ \\
de ventas & & 1.000 .000 & 5.000 .000 & \\
anuales & Hasta & De US\$100.001 & De US\$750.001 & $>$ \\
\hline Montos de & US\$100.000 & hasta US\$ & hasta US\$ & 4.000000 \\
activos & 750.000 & 3.999 .999 & \\
\hline
\end{tabular}

Fuente: Elaboración propia (2021), basado en el Sistema Andino de Estadística de la PYME.

Aquí podemos destacar que en la actualidad por el nuevo régimen simplificado los valores cambian, lo que se mantiene es la cantidad de personal mientras que ahora la normativa expresa que los contribuyentes con ingresos anuales que sean igual o menor a $\$ 3000.000$ serán considerados microempresarios.

En el 2010 ya se publica el Código orgánico de la producción, comercio e inversionesCOPCI (2010) y aquí ya se define plenamente lo que es una microempresa, como está constituida y como se encadena con la normativa internacional, de igual manera en Ley Orgánica de Economía Popular y Solidaria - SEPS (2014), se ubican los productores pequeños que son núcleos económicos populares y solidarios, y también en la ley de compañías se agrega lo que se promulgo en la decisión de la CAN que es la definición de las microempresas, y las empresas empiezan a definirse de acuerdo al tamaño, es decir, número de empleados, número de ventas, valores en costo de activo, en consecuencia en diciembre del 2014 hasta el 2020 ya se encadena en la ley de régimen tributario interno el concepto de microempresa y se promulgan extensiones y beneficios tributarios para la formación de microempresa y la ley orgánica de simplificación y progresividad tributaria define un régimen especial para el sector de las microempresas, pero esto ya con un fin recaudatorio.

En el Ecuador las MIPYMES son el $99.55 \%$ es decir que del total de empresas la mayoría son MIPYMES y si distribuimos esta categoría tenemos que el $90.8 \%$ son microempresas es decir que son empresas que tienen ingresos menores de $\$ 300.000$ o de 1 a 9 empleados, esta es la respuesta de porque la administración tributaria genera un cumulo recaudatorio especialmente para las microempresas pues la mayoría de emprendimientos, está en esta área, las pequeñas empresas representan el 7.2\% y las medianas el 1.6\%.

Otro punto a destacar, según Cohen \& Gabriel (2012), las MIPYMES enfrentan algunas dificultades, como acceso limitado a fuentes de financiamiento, bajos niveles de capacitación de recursos humanos, innovación y desarrollo tecnológico limitados, y baja 
penetración en el mercado internacional. El nivel de productividad es bajo. La baja capacidad asociativa y administrativa son los más importantes, factores que limitan el crecimiento de sus negocios y reducen su productividad y eficiencia en el mercado nacional e internacional.

Por otro lado, Fairlie (2007), buscó determinar si existe una relación estadística entre la innovación empresarial y la generación de valor agregado, donde las comparaciones realizadas en general demostraron que un $82 \%$ de las PYMES que han aplicado algún tipo de innovación en su empresa en los últimos dos años han visto incrementadas sus ventas en relación a sus competidores, mientras que aquellas que no lo hicieron han tenido un incremento de ventas del $27 \%$. Las diferencias en ventas entre empresas del mismo rubro con respecto a aquellas que se innovan constantemente es significativa.

Por su parte, Becerra. et.al ( 2020), sostiene que aunque este impuesto se paga sobre los ingresos brutos, se debe seguir teniendo bien sustentados todos los gastos del giro del negocio, con respecto al análisis de la Ley Orgánica de Simplificación y Progresividad Tributaria, en su análisis indicó que, dentro del grupo de las Mipymes, están los microempresarios, pequeños empresarios y emprendedores, que al analizar profundamente la citada ley, aplicable a este sector, al margen de conocer la utilidad que pueda tener, las mismas tienen problemas desde el año anterior, por cuanto resultaron las más perjudicadas como efecto de las paralización de octubre, por el paro que existió de los transportistas e indígenas y de los sectores sociales, en donde, ya se notó la disminución de sus ingresos, ahora con la nueva ley tributaria, se determina imposiciones, que con el carácter de impositiva, sumada a este época de crisis económica, por la pandemia del covid-19, a nivel no solo nacional, si no mundial, se agravó la situación económica, de allí que si no fuera por la existencia de la moneda del dólar, la economía Ecuatoriana se hubiese hundido visiblemente.

\section{Conclusiones.}

- Después de ver y analizar los resultados de las encuestas a los contribuyentes Microempresarios de la ciudad de Cuenca por el nuevo régimen para microempresas se puede destacar que tiene un nivel de aceptación muy bajo, ya que un punto importante a mencionar es que las MIPYMES enfrentan algunas dificultades, como acceso limitado a fuentes de financiamiento, cortos niveles de capacitación de recursos humanos, innovación y desarrollo tecnológico limitados, y baja penetración en el mercado internacional ya que el nivel de productividad no es muy bueno y la limitada capacidad asociativa y administrativa son los más importantes, factores que abyecta el crecimiento de los negocios y reducen su productividad y eficiencia en el mercado nacional e internacional.

- Como puede observarse el $2 \%$ de impuesto a la renta es uno de los puntos que más ha generado controversia dada la situación en la que nos encontramos por motivo de la pandemia y de los efectos negativos que esto ha generado a la mayoría de negocios, ya que el nivel de ingresos disminuyo drásticamente y tener que pagar un valor extra en la posición actual no es de agrado para la mayoría de 
los contribuyentes como se puede apreciar en la caracterización de las microempresas en la ciudad de Cuenca, por su estructura organizativa, normativa tributaria y por su restringida gestión empresarial estratégica, hace que tenga una alta limitación para un crecimiento sostenido en el tiempo.

- Es necesario una actualización al catastro y reforma de la Ley Orgánica de Simplificación y Progresividad Tributaria, la modificación debe establecer una excepción al pago del impuesto del $2 \%$ sobre las ventas en el caso de los Microempresarios registren pérdidas en el periodo fiscal. Con ello se permitirá la sostenibilidad de miles de microempresarios además de la generación de puestos de trabajo, hoy necesarios para la reactivación económica.

\section{Referencias bibliográficas.}

Arias, F. (2016). El Proyecto de Investigación: Introducción a la metodología científica. ( $7^{\text {a }}$ Edición), Caracas - Venezuela. Editorial El pasillo, C.A.

Altamirano Villacís, Gladys Tatiana. (2012). Tendencia de la tributación a nivel mundial: un debate entre eficiencia y equidad tributaria. Trabajo de investigación como requisito previo a la obtención del título en la Maestría en Administración Tributaria. Quito: IAEN. 151 p.

Asamblea Constituyente. (2008). Constitución de la República del Ecuador. http://goberguayas.gob.ec/pdf/INFORMACIONLEGAL/NORMASDECREACI ON/Norma-Constitucional.pdf

Becerra. et.al (2020, 7 de junio ). Análisis de efectos tributarios en las Mipymes. https://doi.org/10.33262/concienciadigital.v3i2.2.1249

COHEN, M., \& GABRIEL, B. 2012. La situación de las PyMEs en América Latina.

Consulta societaria (2017, 13 de junio ). http://www.ccq.ec/wpcontent/uploads/2017/06/Consulta_Societaria_Junio_2017.pdf

El comercio (2021 16 de enero). Impuesto del 2\% para microempresarios : https://www.elcomercio.com/actualidad/microempresarios-impuesto-renta-sricontribuyentes.html.. ElComercio.com

FAIRLIE, E. (2007). Generación de Valor Agregado en las Pymes a través de la innovación empresarial. Gestión en el tercer milenio. Revista de Investigación de la Facultad de Ciencias Administrativas, Universidad Nacional Mayor San Marcos, 23-27.

Gaceta oficial del acuerdo de Argentina (2009, 24 de agosto). http://intranet.comunidadandina.org/Documentos/gacetas/Gace1743.pdf 
Vol. 5, N², p. 149-169, abril-junio, 2021

Ley de régimen tributario interno (2018) recuperado de : https://www.ces.gob.ec/lotaip/2018/Agosto/Anexos-literala2/LEY\%20DE\%20REGIMEN\%20TRIBUTARIO\%20INTERNO,\%20LRTI.pd f

Ministerio Coordinador de la Producción, El Empleo y la Competitividad (2012), Quito, Ecuador, disponible en: www.produccion.gob.ec

Olmedo, E. (2010). Estructura del Sistema de Control Interno, Ecuador Ibarra.Organización Internacional del Trabajo, Manual de Salud y Asociaciones de Microempresas. (2004): 1ra Edición.

Paula Nicole Roldán (07 de junio, 2017). Tributo. Economipedia.com

Servicio de Rentas Internas (2021), recuperado de: https://www.sri.gob.ec/web/guest/leyorgánica-de-simplificación-y-progresividad-tributaria

Sistema andino de estadística de la pyme (2008, 10 de diciembre). http://www.sice.oas.org/trade/JUNAC/Decisiones/DEC702s.pdf Servicio de rentas internas. (31/05/2020). Normas para el regimen impositivo para microempresas, Obtenido de Servicio de Rentas Internas: https://nmslaw.com.ec/sri-expide-normas-regimen-impositivo-microempresas/

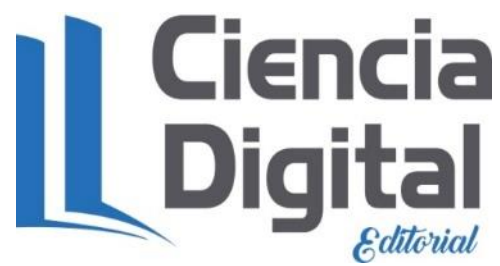




\section{PARA CITAR EL ARTÍCULO INDEXADO.}

Becerra Molina, E., \& Neira Cedeño, M. Ángel. (2021). Análisis de las normativas tributarias 2020, en aplicación con las microempresas de la ciudad de Cuenca. Visionario Digital, 5(2), 149-169. https://doi.org/10.33262/visionariodigital.v5i2.1701

\section{Ciencia}

El artículo que se publica es de exclusiva responsabilidad de los autores y no necesariamente reflejan el pensamiento de la Revista Visionario Digital.

El artículo queda en propiedad de la revista y, por tanto, su publicación parcial y/o total en otro medio tiene que ser autorizado por el director de la Revista Visionario Digital.
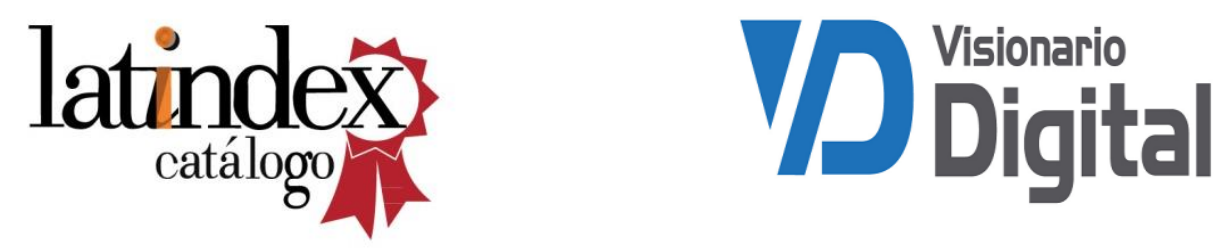